\title{
Experimental investigation on electro-discharge surface modification phenomenon of P20+Ni die steel using green P/M composite electrode
}

\author{
J.L. Ramdatti1 ${ }^{1}$ A.V. Gohil2 and K.G. Dave ${ }^{3}$ \\ 1 Production Engineering Department, Government Engineering College, Bhavnagar -364002, Gujarat, India \\ Phone: +919228133940 \\ 2 Production Engineering Department, Shantilal Shah Engineering College, Bhavnagar - 364060, Gujarat, India \\ ${ }^{3}$ Mechanical Engineering Department, Lalbhai Dalpatbhai Engineering College, Ahmedabad-380015, Gujarat, India
}

ABSTRACT - In the present work, attempts have been made to optimize the EDM process with an aspect of surface modification of AISI P20+Ni die steel using powder metallurgy (P/M) electrode. Experiments have been performed according to central composite rotatable (CCD) design using response surface methodology (RSM). Effects of compaction pressure $\left(C_{p}\right)$, peak current $\left(I_{p}\right)$, pulse-on time $\left(T_{\text {on }}\right)$, and duty cycle $(\tau)$ were correlated with surface roughness (SR) and microhardness $(\mathrm{MH})$. Adequacy of mathematical model has been checked by performing ANOVA. Composite desirability approach was used to obtain optimal set of parameters for minimum SR and maximum $\mathrm{MH}$. The errors between the predicted and experimental value of responses at the optimal set of parameters for SR and $\mathrm{MH}$ maintain within $5.26 \%$ and $-3.64 \%$ respectively. Scanning electron microscope and energy dispersive spectroscopy analysis confirmed the transfer of P/M electrode material on the work surface. The result indicates three times improvement in microhardness of EDMed surface.

\author{
ARTICLE HISTORY \\ Received: 23rd Sept 2019 \\ Revised: $08^{\text {th }}$ Apr 2021 \\ Accepted: $14^{\text {th }}$ Apr 2021

\section{KEYWORDS} \\ EDM; \\ P/M composite electrode; \\ response surface \\ methodology; \\ surface roughness; \\ microhardness; \\ composite desirability.
}

\section{INTRODUCTION}

Electrical Discharge Machine (EDM) [1] has become the most popular and extensively recognised non-traditional machining processes [2] particularly in the die making industries [3]. The process is used to produce very complex shapes irrespective of hardness in the electrically conductive material [4-6]. EDM is a thermoelectric advanced machining process which works based on the principle of tranformation of electric into thermal energy. A very high temperature (8000 to $12000^{\circ} \mathrm{C}$ ) due to discrete electric discharge (sparking action) between a tool (electrode) and work material, leads to melting and partial vaporization of work material and tool at the point of discharge [7]. The process is widely used in automobile, aerospace and medical sectors for machining and finishing of different components [8-10].

Since last decade, the trend towards the use of miniaturization and lightweight components in automobile, aerospace, and railway sectors is continuously increasing. Consequently, metallic components have been replaced by plastic components. Replacement is only possible when plastic material exhibits physical and mechanical properties same as of metal [11]. The presence of hardest constituents such as mica, silica, glass fibre etc. in the plastic improves mechanical properties. However, the presence of hardest constituents deteriorates the life of moulds and dies due to wear and corrosion [12]. This influences greatly on the cost of moulds and dies. Hence, improvements in mould and die life is important for composite plastic processing industries. Recently, the surface treatment processes such as CVD, PVD, plasma coating and Electro Plating are used to enhance the life of die and mould $[8,13-15]$.

However, these secondary surface treatments are very expensive and time-consuming; further, there is addition of cost and time due to removal of the recast layer of EDMed surface prior to performing secondary surface treatments [16]. These issues have been resolved if modification of die surface is possible while machining on EDM. The EDM electrode manufactured using powder metallurgy has been observed as feasible alternative than conventional electrode because it helps to improves die life due to the modification of recast layer, reduction of cost and time due to the elimination of secondary surface treatments [17-19].

Attempts have been made by various researchers to explore the feasibility of migration of the hardest constituents either from P/M electrode or by adding various conductive powders into the dielectric. Mohri et al. (1991) present a surface modification treatment using carbon steel as work material with composite-structured electrode, results in defects free, corrosion and wear resistant surface [20]. Singh B. et al. (2012) performed experimentation on AA6061/SiCp using $\mathrm{Cu}-\mathrm{W}$ electrode, results shows high microhardness and improved thick recast layer due to the migration of electrode materials [21]. Cogun et al. (2015) reported notable improvements in abrasive wear resistance and other machining characteristics such as MRR, TWR and SR while process performed with $\mathrm{Cu}$ and $\mathrm{Cu}-\mathrm{TaC}$ powder metallurgy electrode. High microhardness has been observed with $\mathrm{Cu}-\mathrm{TaC}$ P/M electrode as compared to $\mathrm{Cu}$ electrode [24]. Gangadhar et al. (1991) observed changes in surface topography of work material while machined with $\mathrm{Cu}$-Sn powder compact tool [25]. Beri et al. (2008) carried out optimization of EDM process performed with $\mathrm{Cu}-\mathrm{W}$ electrode manufactured by the P/M 
process. Performance of $\mathrm{P} / \mathrm{M}$ electrode has been found better as compared to conventional Cu electrode [26]. Bhattacharya et al. (2013) carried out the surface characterization of EDMed surface and reported migration of silicon, graphite and tungsten powder from dielectric [27]. Singh et al. (2012) investigates the phenomenon of surface alloying by EDM. The result indicates $83 \%$ high microhardness of the alloyed surface as compared to conventional process [28]. Kumar et al. (2009) performed an experiment on OHNS die steel with manganese powder mixed in kerosene as a dielectric to investigate surface properties [29]. T. A. EL Tweel (2009) carried out multi-response optimization of EDM process performed using Al-Cu-Si-TiC P/M electrode. Optimization of MRR and TWR reported using composite desirability approach. A good agreement observed between predicted and experimental results [30]. Furutani et al. (2001) describes the influence of EDM parameters on the TiC deposition process by EDM with Ti powder suspended in EDM oil. Improvements of surface morphology and surface properties were observed due to the migration of elements either from P/M electrode or dielectric while machining on EDM [31].

Attempts have been made by various researchers to develop an empirical model of the EDM process performed using a conventional electrode. However, need to develop a mathematical model for EDM process performed as aspects of surface alloying of AISI P20+Ni die steel using RSM. Though the feasibility of surface alloying using P/M electrode [3234] has been reported by various researchers but some issues related to it are yet to be explored before the industrialization of the present technique. Limited numbers of studies are available in literature related to the surface modification of AISI P20+Ni die steel using P/M electrode. Similarly, limited literature was available on multi-objective optimization of surface alloying by EDM using P/M tool. Therefore, following attempts have been made in present experimental work:

- Evaluate EDM process responses such as SR and MH as an aspect of the surface alloying phenomenon.

- Develop a regression model for SR and MH using RSM which helps to predict the value of responses while varying input parameters.

- $\quad$ Perform ANOVA to predict the significance of input parameters and develop three-dimensional response surface plots.

- Multi-objective optimization of responses using composite desirability approach.

\section{EXPERIMENTATION}

\section{Preparation of P/M Electrode}

Present experimental work has been carried out on EDM using five different electrodes. Powder metallurgy process is used to manufacture electrode from mixture of three metallic powder of Copper $(\mathrm{Cu})$, tungsten $(\mathrm{W})$ and $\mathrm{Silicon}(\mathrm{Si})$ taken in 75:23:2 by weight percentage respectively. Three powders was mixed properly using mortar and pestle. Scanning electron microscopy (SEM) has been carried out to confirm the uniformity of mixture. The SEM images of mixture with different magnification are shown in Figure 1.
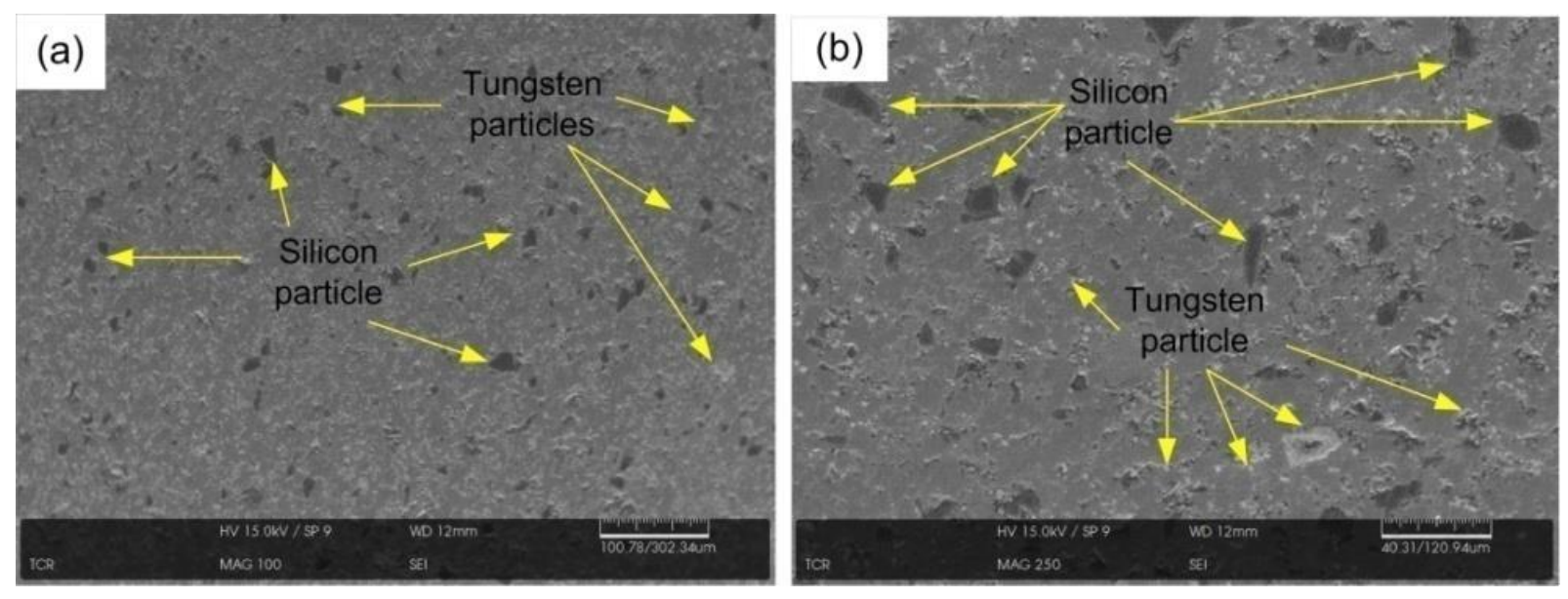

Figure 1. SEM images of $\mathrm{Cu}-\mathrm{W}-\mathrm{Si}$ powder mixture

Proper distribution of tungsten (white) and silicon (black) particles in copper matrix has been observed during SEM. There after the mixture was pressed in compaction die $(\phi 19 \mathrm{~mm})$ at different compaction pressure using hand operated hydraulic press. Various electrode parameters with their value are given in Table 1. 
Table 1. Parameters considered for preparing P/M electrode

\begin{tabular}{clc}
\hline Parameter & & Description \\
\hline Powder proportions $(\mathrm{Cu}: \mathrm{W}: \mathrm{Si})$ & $:$ & $75: 23: 2 \% \mathrm{wt}$ \\
Powder particle size $(\mathrm{Cu}: \mathrm{W}: \mathrm{Si})$ & $:$ & $45: 8: 45 \mathrm{microns}$ \\
Compaction pressure & $:$ & $125-325 \mathrm{~kg} / \mathrm{cm}^{2}$ \\
Holding time & $:$ & $2 \mathrm{~min}$. \\
Compact dimensions & $:$ & $19 \mathrm{~mm}$ diameter $\& 10 \mathrm{~mm}$ height
\end{tabular}

The P/M electrodes produced in hydraulic press using different levels of compaction pressure are shown in Figure 3(a). The EDS was carried out to confirm the elements presents in P/M electrode [35]. Traces of copper, tungsten and silicon were observed during the EDS analysis. The EDS spectrum of P/M electrode with compositions is shown in Figure 2.

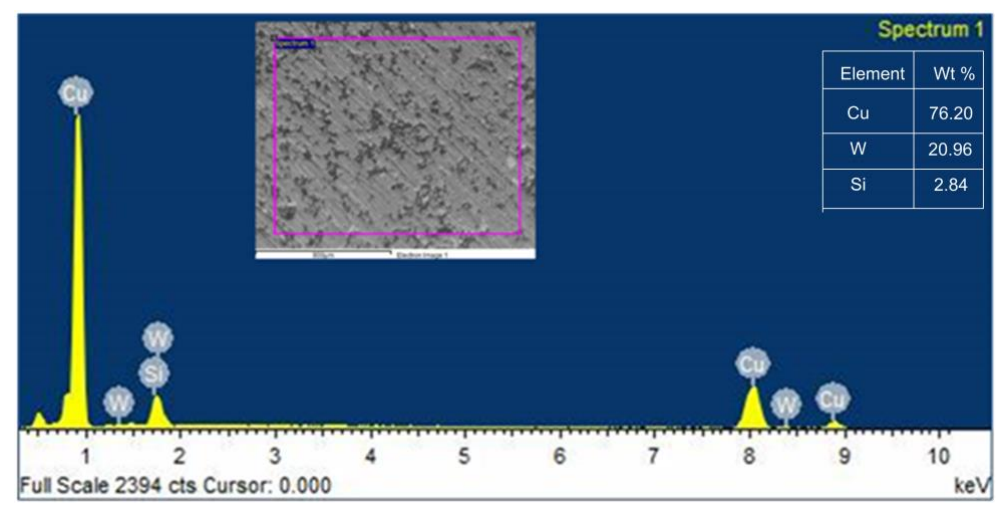

Figure 2. EDS spectrum of $\mathrm{P} / \mathrm{M}$ electrode

\section{Experimental Procedure}

In this experimental study, trials were performed on AISI P20+Ni steel using a unique tool (electrode) made up through powder metallurgy process. Two responses: surface roughness and microhardness have been recorded by considering four input variables such as compaction pressure $\left(\mathrm{C}_{\mathrm{p}}\right)$, peak current $\left(\mathrm{I}_{\mathrm{p}}\right)$, pulse on time $\left(\mathrm{T}_{\text {on }}\right)$ and duty cycle $(\tau)$. Experiments were performed on die-sinker EDM (Make: Maruti Machine Tools, India. Model: M25-6040). Figures 3(b) and (c) show the P/M electrode holder and AISI P20+Ni steel specimens EDMed using P/M electrodes respectively. The substrates were sized of $25 \mathrm{~mm} \times 25 \mathrm{~mm} \times 10 \mathrm{~mm}$ thick and finished on surface grinder prior to experimentation. Table 2 shows the chemical compositions of AISI P20+Ni die steel. The working conditions maintained during the performance of experiments with its detailed descriptions are given in Table 3.

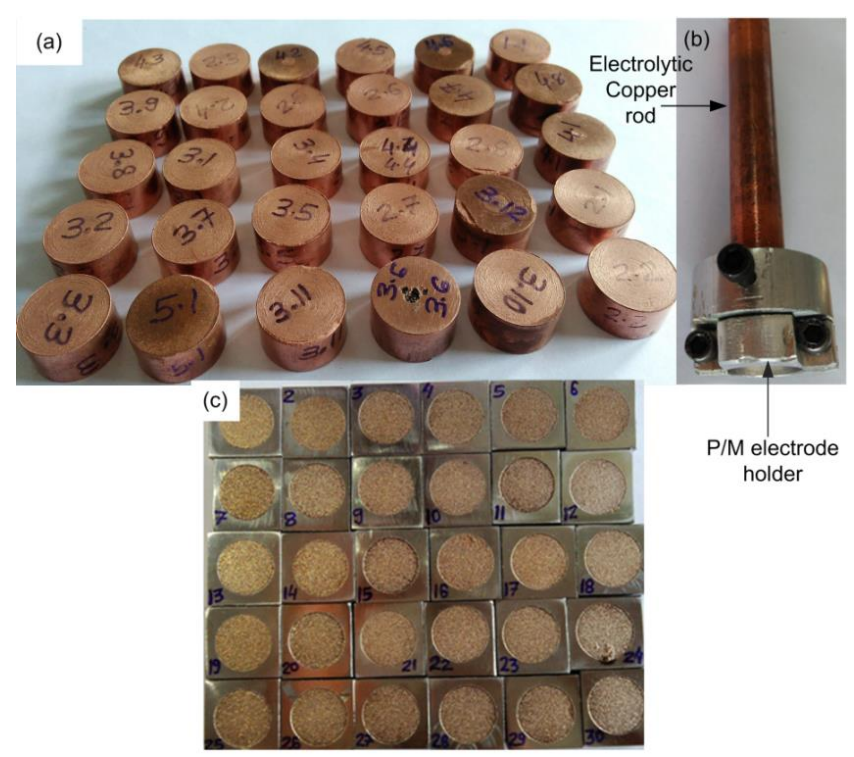

Figure 3. (a) Powder metallurgy electrode, (b) P/M electrode holder and (c) Specimens of AISI P20+Ni steel machined using $\mathrm{P} / \mathrm{M}$ electrode 
Table 2. Chemical compositions for AISI P20+Ni die steel

\begin{tabular}{ccccccccccc}
\hline Element & $\mathrm{C}$ & $\mathrm{Si}$ & $\mathrm{Mn}$ & $\mathrm{P}$ & $\mathrm{S}$ & $\mathrm{Cr}$ & $\mathrm{Mo}$ & $\mathrm{Ni}$ & $\mathrm{Cu}$ & $\mathrm{V}$ \\
\hline $\mathrm{Wt} \%$ & 0.36 & 0.27 & 1.25 & 0.01 & 0.006 & 1.86 & 0.17 & 0.95 & 0.071 & 0.065 \\
\hline
\end{tabular}

Table 3. Working condition of experimentation

\begin{tabular}{ccc}
\hline Working conditions & & Description \\
\hline Workpiece material & $:$ & AISI P20+Ni die steel \\
Electrode composition & $:$ & $75 \% \mathrm{Cu}+23 \% \mathrm{~W}+2 \% \mathrm{Si}$ (\% of weight) \\
Polarity & $:$ & Negative Electrode \\
Dielectric fluid & $:$ & EDM Oil (Pacific oil 300) \\
Flushing type & $:$ & Side flushing \\
Flushing pressure & $:$ & $0.75 \mathrm{~kg} / \mathrm{cm}^{2}$ \\
Processing time & $:$ & 10 minutes \\
\hline
\end{tabular}

Deposited carbon and debris was removed from work surface using acetone. Surface roughness tester "Surftest SJ210 (Make: Mitutoyo, Japan) was used to measure surface roughness (Ra value) of EDMed surface. Three measurements of roughness in different directions were recorded and the mean value of the same was considered for developing surface roughness model. Microhardness of substrate was measured before and after EDMed using digital microhardness tester 7005-B (Make: Vaisesika, India). Microhardness was measured at three different positions under the load condition of $300 \mathrm{gf}$ with 15 seconds dwell time. The mean value of microhardness was considered for further developing the MH model. Microhardness of the base material was measured 322 VHN.

\section{Experimental Planning}

In present experimental work levels of four process variables such as compaction pressure $\left(\mathrm{C}_{\mathrm{p}}\right)$, peak current $\left(\mathrm{I}_{\mathrm{p}}\right)$, pulse on time $\left(\mathrm{T}_{\mathrm{on}}\right)$, and duty cycle $(\tau)$ were decided based on rigorous literature reviews and performing numbers of pilot experiment. Effects of selected process variables have been studied on SR and MH. Each parameter has five levels with their respective unit is shown in Table 4.

Table 4. Input parameters and their levels

\begin{tabular}{ccccccc}
\hline \multirow{2}{*}{ Parameter } & Unit & \multicolumn{5}{c}{ Levels } \\
\cline { 3 - 7 } & & -2 & -1 & 0 & 1 & 2 \\
\hline Compaction pressure $\left(\mathrm{C}_{\mathrm{p}}\right)$ & $\left(\mathrm{kg} / \mathrm{cm}^{2}\right)$ & 125 & 175 & 225 & 275 & 325 \\
Peak Current $\left(\mathrm{I}_{\mathrm{p}}\right)$ & $($ Amp. $)$ & 6 & 9 & 12 & 15 & 18 \\
Pulse on time $\left(\mathrm{T}_{\text {on }}\right)$ & $(\mu \mathrm{s})$ & 50 & 70 & 90 & 110 & 130 \\
Duty cycle $(\tau)$ & $(\%)$ & 75 & 80 & 85 & 90 & 95 \\
\hline
\end{tabular}

Experiments were performed according to design matrix developed using RSM. A second order (rotatable) central composite design (CCD) was considered for performing 30 numbers of experiments. Distribution of $2 \beta$ fractional points was decided based on 16 points at corner, 6 points at the centre and 8 axial points located at $2 \alpha$ level. Experimental design matrix and mean of interested responses are shown in Table 5.

\section{ADEQUACY CHECKING AND MATHEMATICAL MODELLING OF RESPONSES BASED ON RSM}

Response surface methodology (RSM) is mainly used for modelling and analysing the industrial process. It is a set of collection of mathematical and statistical techniques. Based on RSM the mathematical model of all responses can be expressed as,

$$
Y_{i}=f\left(C_{p}, I_{p}, T_{o n}, \tau\right)+\varepsilon
$$

Where $\mathrm{Y}_{\mathrm{i}}$ is the response and $\mathrm{C}_{\mathrm{p}}, \mathrm{I}_{\mathrm{p}}, \mathrm{T}_{\text {on }}$ and $\tau$ are coded value of process parameters while $\varepsilon$ is the fitting error for $\mathrm{i}^{\text {th }}$ observations. The responses were modelled as per second order quadratic polynomial regression Eq. (2). 


$$
\begin{array}{r}
Y=\alpha_{0}+\alpha_{1} C_{p}+\alpha_{2} I_{p}+\alpha_{3} T_{\text {on }}+\alpha_{4} \tau+\alpha_{5} C_{p} I_{p}+\alpha_{6} C_{p} T_{\text {on }}+\alpha_{7} C_{p} \tau+\alpha_{8} I_{p} T_{\text {on }}+ \\
\alpha_{9} I_{p} \tau+\alpha_{10} T_{\text {on }} \tau+\alpha_{11} C_{p}^{2}+\alpha_{12} I_{p}^{2}+\alpha_{13} T_{o n}^{2}+\alpha_{14} \tau^{2}+\varepsilon
\end{array}
$$

Where $C_{p}, I_{p}, T_{o n}$, and $\tau$ are input parameter for response $Y$ and $\alpha_{i}=$ regression coefficient (where $i=1,2,3 \ldots n$ ), $\varepsilon=$ random error, which is normally distributed with mean as per observed response. The statistical software Design Expert 10 programming was used to perform F-test and also used to plot actual versus predicted responses to check the validity of the developed model before optimization.

\begin{tabular}{|c|c|c|c|c|c|c|c|c|c|c|c|}
\hline \multirow{3}{*}{$\begin{array}{l}\text { Exp. } \\
\text { No. }\end{array}$} & \multirow{3}{*}{$\begin{array}{l}\text { Run } \\
\text { Order }\end{array}$} & \multicolumn{8}{|c|}{ Input process parameters } & \multicolumn{2}{|c|}{$\begin{array}{c}\text { Mean Value of } \\
\text { Responses }\end{array}$} \\
\hline & & \multicolumn{2}{|c|}{$\begin{array}{l}\text { Compaction } \\
\text { Pressure }\left(C_{p}\right)\end{array}$} & \multicolumn{2}{|c|}{$\begin{array}{c}\text { Peak Current } \\
\left(\mathrm{I}_{\mathrm{p}}\right)\end{array}$} & \multicolumn{2}{|c|}{$\begin{array}{l}\text { Pulse on time } \\
\qquad\left(\mathrm{T}_{\mathrm{on}}\right)\end{array}$} & \multicolumn{2}{|c|}{$\begin{array}{c}\text { Duty Cycle } \\
(\tau)\end{array}$} & \multirow{2}{*}{$\begin{array}{c}\mathrm{SR} \\
(\mu \mathrm{m})\end{array}$} & \multirow{2}{*}{$\begin{array}{c}\mathrm{MH} \\
(\mathrm{HVN})\end{array}$} \\
\hline & & Actual & Coded & Actual & Coded & Actual & Coded & Actual & Coded & & \\
\hline 1 & 12 & 175 & -1 & 9 & -1 & 70 & -1 & 80 & -1 & 5.635 & 886 \\
\hline 2 & 6 & 275 & 1 & 9 & -1 & 70 & -1 & 80 & -1 & 4.755 & 831 \\
\hline 3 & 9 & 175 & -1 & 15 & 1 & 70 & -1 & 80 & -1 & 8.192 & 1026 \\
\hline 4 & 28 & 275 & 1 & 15 & 1 & 70 & -1 & 80 & -1 & 7.481 & 936 \\
\hline 5 & 4 & 175 & -1 & 9 & -1 & 110 & 1 & 80 & -1 & 6.443 & 852 \\
\hline 6 & 27 & 275 & 1 & 9 & -1 & 110 & 1 & 80 & -1 & 5.387 & 791 \\
\hline 7 & 14 & 175 & -1 & 15 & 1 & 110 & 1 & 80 & -1 & 8.684 & 908 \\
\hline 8 & 20 & 275 & 1 & 15 & 1 & 110 & 1 & 80 & -1 & 8.126 & 883 \\
\hline 9 & 11 & 175 & -1 & 9 & -1 & 70 & -1 & 90 & 1 & 6.477 & 1103 \\
\hline 10 & 16 & 275 & 1 & 9 & -1 & 70 & -1 & 90 & 1 & 5.119 & 868 \\
\hline 11 & 2 & 175 & -1 & 15 & 1 & 70 & -1 & 90 & 1 & 9.831 & 1189 \\
\hline 12 & 22 & 275 & 1 & 15 & 1 & 70 & -1 & 90 & 1 & 8.614 & 1092 \\
\hline 13 & 5 & 175 & -1 & 9 & -1 & 110 & 1 & 90 & 1 & 7.387 & 1021 \\
\hline 14 & 19 & 275 & 1 & 9 & -1 & 110 & 1 & 90 & 1 & 5.882 & 793 \\
\hline 15 & 29 & 175 & -1 & 15 & 1 & 110 & 1 & 90 & 1 & 10.605 & 1056 \\
\hline 16 & 15 & 275 & 1 & 15 & 1 & 110 & 1 & 90 & 1 & 9.481 & 924 \\
\hline 17 & 10 & 125 & -2 & 12 & 0 & 90 & 0 & 85 & 0 & 8.263 & 1059 \\
\hline 18 & 25 & 325 & 2 & 12 & 0 & 90 & 0 & 85 & 0 & 5.985 & 861 \\
\hline 19 & 18 & 225 & 0 & 6 & -2 & 90 & 0 & 85 & 0 & 4.235 & 821 \\
\hline 20 & 7 & 225 & 0 & 18 & 2 & 90 & 0 & 85 & 0 & 10.323 & 1094 \\
\hline 21 & 30 & 225 & 0 & 12 & 0 & 50 & -2 & 85 & 0 & 6.934 & 974 \\
\hline 22 & 21 & 225 & 0 & 12 & 0 & 130 & 2 & 85 & 0 & 8.617 & 822 \\
\hline 23 & 13 & 225 & 0 & 12 & 0 & 90 & 0 & 75 & -2 & 5.882 & 869 \\
\hline 24 & 23 & 225 & 0 & 12 & 0 & 90 & 0 & 95 & 2 & 8.266 & 1071 \\
\hline 25 & 26 & 225 & 0 & 12 & 0 & 90 & 0 & 85 & 0 & 7.628 & 846 \\
\hline 26 & 3 & 225 & 0 & 12 & 0 & 90 & 0 & 85 & 0 & 7.573 & 837 \\
\hline 27 & 1 & 225 & 0 & 12 & 0 & 90 & 0 & 85 & 0 & 7.591 & 843 \\
\hline 28 & 8 & 225 & 0 & 12 & 0 & 90 & 0 & 85 & 0 & 7.683 & 849 \\
\hline 29 & 24 & 225 & 0 & 12 & 0 & 90 & 0 & 85 & 0 & 7.671 & 831 \\
\hline 30 & 17 & 225 & 0 & 12 & 0 & 90 & 0 & 85 & 0 & 7.622 & 841 \\
\hline
\end{tabular}

Table 5. Experimental design matrix and results of responses 
Analysis of variance (ANOVA) was performed to check the adequacies of the developed model and find the significance of individual parameters on responses. The result of ANOVA for developed SR model is shown in Table 6. The calculated F-value for predicted SR model is 765.61 that indicates significant model. There is a possibility of $0.01 \%$ larger F-value due to noise. In this case, $\mathrm{C}_{\mathrm{p}}, \mathrm{I}_{\mathrm{p}}, \mathrm{T}_{\mathrm{on}}, \tau, \mathrm{C}_{\mathrm{p}} \mathrm{I}_{\mathrm{p}}, \mathrm{C}_{\mathrm{p}} \tau, \mathrm{I}_{\mathrm{p}} \tau, \mathrm{T}_{\mathrm{on}} \tau, \mathrm{C}_{\mathrm{p}}{ }^{2}, \mathrm{I}_{\mathrm{p}}{ }^{2}, \mathrm{~T}_{\mathrm{on}}{ }^{2}, \tau^{2}$ are significant terms (P-value less than 0.05). The "lack of fit" for F-value is 5.10 which indicate lack of fit is significant relative to the pure error. There is a good agreement between "Pred-R-squared" (0.9925) and "Adj- R- squared" (0.9973) with the difference less than 0.2. It is desirable for "Adeq precision" ratio greater than 4. In this case "Adeq precision" ratio is 107.325 which indicate an adequate signal [36].

The result of ANOVA for developed $\mathrm{MH}$ model represented in Table 7. The calculated F-value for predicted $\mathrm{MH}$ model is 54.00 that indicate significant model. There is a possibility of $0.01 \%$ larger F-value due to noise. In this case, $\mathrm{C}_{\mathrm{p}}, \mathrm{I}_{\mathrm{p}}, \mathrm{T}_{\mathrm{on}}, \tau, \mathrm{C}_{\mathrm{p}} \mathrm{I}_{\mathrm{p}}, \mathrm{C}_{\mathrm{p}} \tau, \mathrm{I}_{\mathrm{p}} \mathrm{T}_{\text {on }}, \mathrm{T}_{\text {on }} \tau, \mathrm{C}_{\mathrm{p}}{ }^{2}, \mathrm{I}_{\mathrm{p}}{ }^{2}, \mathrm{~T}_{\text {on }}{ }^{2}$, and $\tau^{2}$ are significant terms (P-value less than 0.05). The "lack of fit $\mathrm{F}-$ value" is 16.50 indicates lack of fit is significant relative to the pure error. There is a good agreement between "Pred-Rsquared" (0.8904) and "Adj- R- squared" (0.9624). It is desirable for "Adeq precision" ratio greater than 4. In this case "Adeq precision" ratio is 27.563 which indicate an adequate signal [37].

From above statistical inferences after removal of the non-significant terms (whose P-value > 0.05 in ANOVA tables of SR and $\mathrm{MH}$ ) the final regressions equations in form of actual terms for SR and MH are represented in Eqs. (3) and (4).

Table 6. ANOVA for surface roughness

\begin{tabular}{|c|c|c|c|c|c|}
\hline Source & $\begin{array}{l}\text { Sum of } \\
\text { Squares }\end{array}$ & $\mathrm{df}$ & $\begin{array}{c}\text { Mean } \\
\text { Square }\end{array}$ & F-Value & $\begin{array}{l}\text { P- value } \\
\text { Prob }>F\end{array}$ \\
\hline Model & 74.51 & 14 & 5.32 & 765.61 & $<0.0001^{*}$ \\
\hline $\mathrm{C}_{\mathrm{p}}$ & 7.00 & 1 & 7.00 & 1007.56 & $<0.0001^{*}$ \\
\hline $\mathrm{I}_{\mathrm{p}}$ & 54.32 & 1 & 54.32 & 7813.76 & $<0.0001^{*}$ \\
\hline $\mathrm{T}_{\text {on }}$ & 3.57 & 1 & 3.57 & 513.65 & $<0.0001 *$ \\
\hline$\tau$ & 7.55 & 1 & 7.55 & 1086.12 & $<0.0001 *$ \\
\hline $\mathrm{C}_{\mathrm{p}} \mathrm{I}_{\mathrm{p}}$ & 0.088 & 1 & 0.088 & 12.71 & $0.0028 *$ \\
\hline $\mathrm{C}_{\mathrm{p}} \mathrm{T}_{\text {on }}$ & 3.706E-004 & 1 & 3.706E-004 & 0.053 & 0.8205 \\
\hline $\mathrm{C}_{\mathrm{p}} \tau$ & 0.25 & 1 & 0.25 & 35.93 & $<0.0001^{*}$ \\
\hline $\mathrm{I}_{\mathrm{p}} \mathrm{T}_{\mathrm{on}}$ & 7.014E-003 & 1 & 7.014E-003 & 1.01 & 0.3311 \\
\hline $\mathrm{I}_{\mathrm{p}} \tau$ & 0.72 & 1 & 0.72 & 104.12 & $<0.0001^{*}$ \\
\hline $\mathrm{T}_{\text {on }} \tau$ & 0.034 & 1 & 0.034 & 4.88 & $0.0431 *$ \\
\hline $\mathrm{C}_{\mathrm{p}}{ }^{2}$ & 0.36 & 1 & 0.36 & 51.87 & $<0.0001^{*}$ \\
\hline $\mathrm{I}_{\mathrm{p}}^{2}$ & 0.16 & 1 & 0.16 & 22.73 & $0.0002 *$ \\
\hline $\mathrm{T}_{\text {on }}{ }^{2}$ & 0.064 & 1 & 0.064 & 9.17 & $0.0085^{*}$ \\
\hline$\tau^{2}$ & 0.44 & 1 & 0.44 & 63.80 & $<0.0001 *$ \\
\hline Residual & 0.10 & 15 & $6.951 \mathrm{E}-003$ & & \\
\hline Lack of Fit & 0.095 & 10 & $9.496 \mathrm{E}-003$ & 5.10 & 0.0430 \\
\hline Pure Error & $9.304 \mathrm{E}-003$ & 5 & $1.861 \mathrm{E}-003$ & & \\
\hline Cor Total & 74.61 & 29 & & & \\
\hline \multicolumn{3}{|c|}{ R-Squared $=0.9986$} & & \multicolumn{2}{|c|}{ Pred R-Squared $=0.9925$} \\
\hline \multicolumn{3}{|c|}{ Adeq Precision $=107.325$} & & \multicolumn{2}{|c|}{ Adj R-Squared $=0.9973$} \\
\hline * Significant & $(\mathrm{P}<0.05)$ & & & & \\
\hline
\end{tabular}


Table 7. ANOVA for microhardness

\begin{tabular}{|c|c|c|c|c|c|}
\hline Source & $\begin{array}{l}\text { Sum of } \\
\text { Squares }\end{array}$ & df & $\begin{array}{l}\text { Mean } \\
\text { Square }\end{array}$ & F-Value & $\begin{array}{l}\text { P- value } \\
\text { Prob }>\text { F }\end{array}$ \\
\hline Model & $3.578 \mathrm{E}+005$ & 14 & 25557.17 & 54.00 & $<0.0001 *$ \\
\hline $\mathrm{C}_{\mathrm{p}}$ & 72490.04 & 1 & 72490.04 & 153.17 & $<0.0001 *$ \\
\hline $\mathrm{I}_{\mathrm{p}}$ & 83898.38 & 1 & 83898.38 & 177.27 & $<0.0001 *$ \\
\hline $\mathrm{T}_{\mathrm{on}}$ & 42588.38 & 1 & 42588.38 & 89.99 & $<0.0001 *$ \\
\hline$\tau$ & 74705.04 & 1 & 74705.04 & 157.85 & $<0.0001 *$ \\
\hline $\mathrm{C}_{\mathrm{p}} \mathrm{I}_{\mathrm{p}}$ & 3570.06 & 1 & 3570.06 & 7.54 & $0.0150 *$ \\
\hline $\mathrm{C}_{\mathrm{p}} \mathrm{T}_{\mathrm{on}}$ & 45.56 & 1 & 45.56 & 0.096 & 0.7606 \\
\hline $\mathrm{C}_{\mathrm{p}} \tau$ & 13282.56 & 1 & 13282.56 & 28.07 & $<0.0001 *$ \\
\hline $\mathrm{I}_{\mathrm{p}} \mathrm{T}_{\mathrm{on}}$ & 3630.06 & 1 & 3630.06 & 7.67 & $0.0143^{*}$ \\
\hline $\mathrm{I}_{\mathrm{p}} \tau$ & 473.06 & 1 & 473.06 & 1.00 & 0.3333 \\
\hline $\mathrm{T}_{\mathrm{on}} \tau$ & 2943.06 & 1 & 2943.06 & 6.22 & $0.0248 *$ \\
\hline $\mathrm{C}_{\mathrm{p}}^{2}$ & 24531.67 & 1 & 24531.67 & 51.83 & $<0.0001 *$ \\
\hline $\mathrm{I}_{\mathrm{p}}^{2}$ & 23517.03 & 1 & 23517.03 & 49.69 & $<0.0001 *$ \\
\hline $\mathrm{T}_{\text {on }}^{2}$ & 5692.53 & 1 & 5692.53 & 12.03 & $0.0034 *$ \\
\hline$\tau^{2}$ & 28582.74 & 1 & 28582.74 & 60.39 & $<0.0001 *$ \\
\hline Residual & 7099.08 & 15 & 473.27 & & \\
\hline Lack of Fit & 6890.25 & 10 & 689.02 & 16.50 & 0.0032 \\
\hline Pure Error & 208.83 & 5 & 41.77 & & \\
\hline Cor Total & $3.649 \mathrm{E}+005$ & 29 & & & \\
\hline \multicolumn{3}{|c|}{ R-Squared $=0.9805$} & & \multicolumn{2}{|c|}{ Adj R-Squared $=0.9624$} \\
\hline \multicolumn{3}{|c|}{ Pred R-Squared $=0.8904$} & & \multicolumn{2}{|c|}{ Adeq Precision $=27.563$} \\
\hline *Significant & $\mathrm{P}<0.05)$ & & & & \\
\hline
\end{tabular}

$$
\begin{gathered}
\mathbf{S R}=7.63-1.08 \mathrm{C}_{\mathrm{p}}+3.01 \mathrm{I}_{\mathrm{p}}+0.77 \mathrm{~T}_{\text {on }}+1.12 \tau+0.30 \mathrm{C}_{\mathrm{p}} \mathrm{I}_{\mathrm{p}}-0.50 \mathrm{C}_{\mathrm{p}} \tau+0.85 \mathrm{I}_{\mathrm{p}} \tau+0.18 \mathrm{~T}_{\text {on }} \tau-0.46 \\
\mathrm{C}_{\mathrm{p}}{ }^{2}-0.30 \mathrm{I}_{\mathrm{p}}^{2}+0.19 \mathrm{~T}_{\text {on }}{ }^{2}-0.51 \tau^{2}
\end{gathered}
$$

The adequacy of developed mathematical model based on regression using RSM for SR and MH have been examined using residual analysis. The Figure 4(a) and (b) indicate plot of normal \% probability vs. internally studentized residuals and actual SR vs. predicted results of SR. The plots of results indicate that the actual SR vs. predicted SR data spread approximately linear, confirm a good agreement between predicted and actual values of SR. Hence, proposed surface roughness model is significant. 


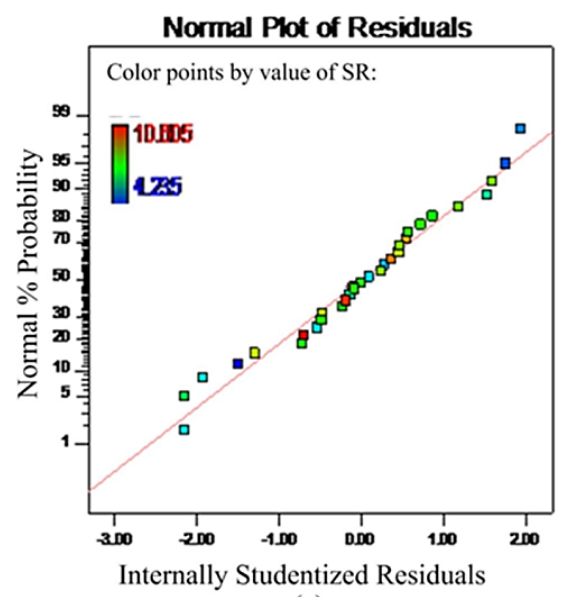

(a)

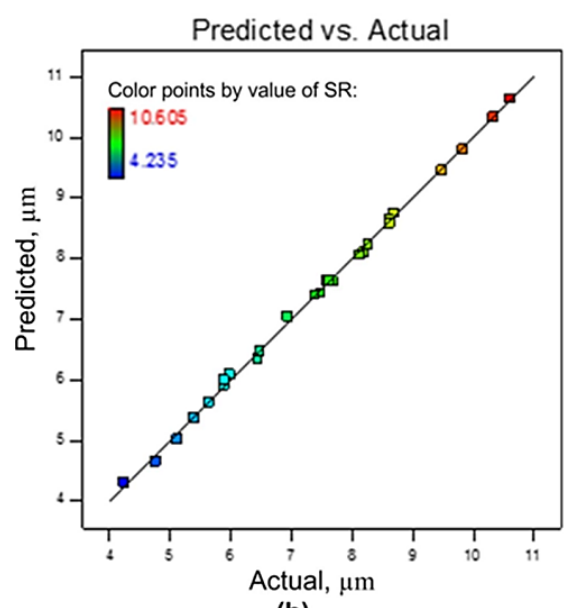

(b)

Figure 4. (a) Normal probability plot of the residual for SR, (b) Actual vs. Predicted response for SR

Similarly, the Figure 5(a) and (b) indicate plot of normal \% probability vs. internally studentized residuals and actual vs. predicted MH. The result indicates that the actual MH vs. predicted MH data spread approximately linear which indicate a good agreement between predicted and actual values of MH. Hence, proposed MH model is also significant. The results of statistical tests indicate that the developed models are adequate for the surface roughness and microhardness and the same can be extended for further analysis [38].

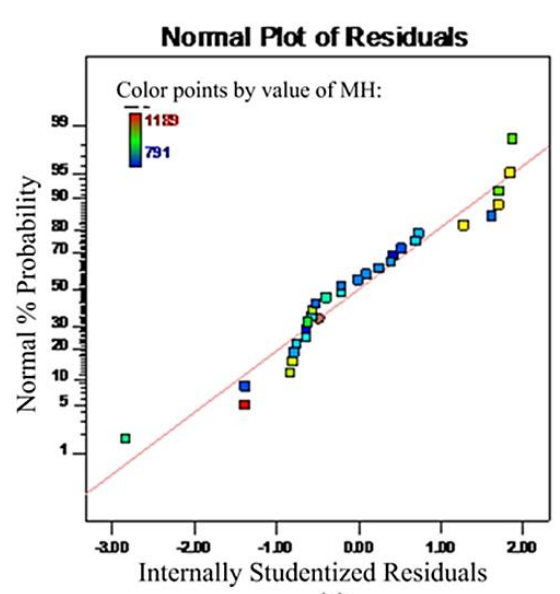

(a)

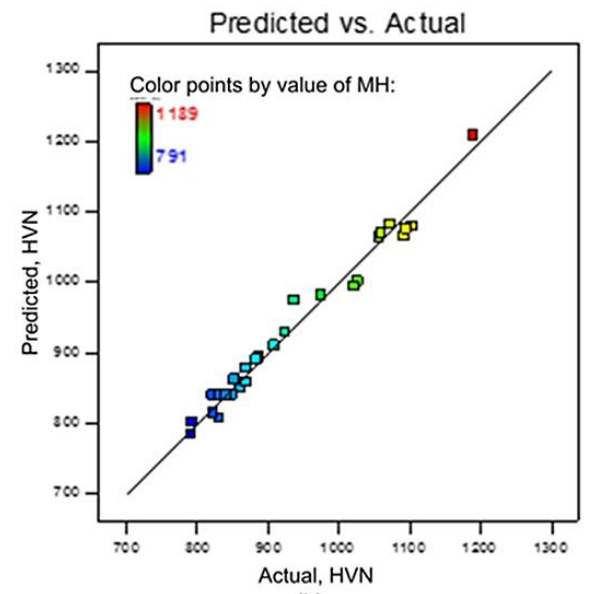

(b)

Figure 5. (a) Normal probability plot of the residual for MH and (b) Actual against predicted response for microhardness

\section{INFLUENCE OF PARAMETERS ON RESPONSES}

The influence and correlation of selected process variables with output measures such as SR and MH have been investigated using three-dimensional surface plots based on the RSM quadratic model.

\section{Effect of Process Parameters on SR}

Reliability of component mainly depends on the quality of the surface obtained during machining. Poor surface quality is responsible for initiating crack and corrosion, which results in early failure of the component. Further, rough surface has always adverse effects on tribological behaviour. Three-dimensional surface plots to study the relation between input process parameters with surface roughness are shown in Figures 6(a) and (b). The peak current $\left(\mathrm{I}_{\mathrm{p}}\right)$ and pulse on time $\left(\mathrm{T}_{\mathrm{on}}\right)$ are the most effective parameters. When peak current increases from $6 \mathrm{~A}$ to $18 \mathrm{~A}$, the surface roughness increases from $4.2 \mu \mathrm{m}$ to $10.6 \mu \mathrm{m}$. This increase in SR with a high value of peak current is due to the increase in discharge energy that facilitates the melting and vaporizing of work material in the sparking area. Transfer of maximum amount of heat energy due to high peak current is able to improve disintegration of work material resulting deterioration of work surface during machining [39]. 


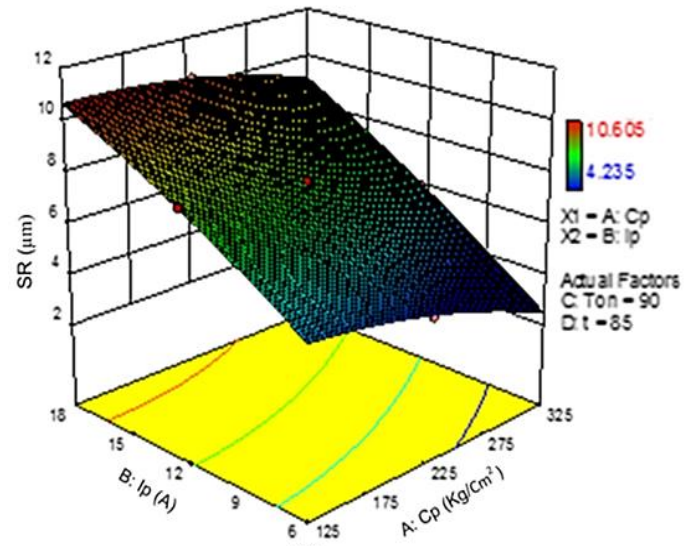

(a)

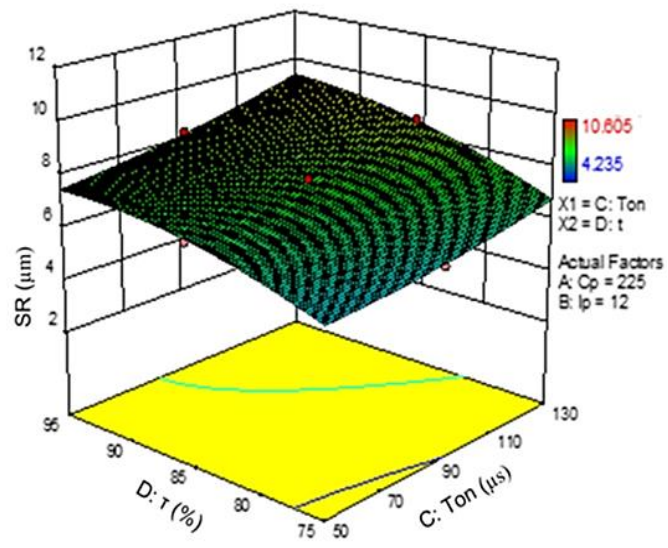

(b)

Figure 6. (a) Surface plot of SR vs. compaction pressure and peak current and (b) Surface plot of SR vs. pulse on time and duty cycle

\section{Effect of Process Parameters on MH}

Die and tool used to produce components from composite plastics are always subjected to high abrasion, wear, pressure, and temperature. Therefore it is desirable to have good wear resistance ability in steel used to manufacture die and tool. In this experimental work, efforts have been carried out to increase the hardness of AISI P20+Ni die steel machined on EDM using P/M electrode. Three-dimensional surface plots to study the effects of input parameters such as $\mathrm{C}_{\mathrm{p}}, \mathrm{I}_{\mathrm{p}}, \mathrm{T}_{\text {on }}$ and $\tau$ on $\mathrm{MH}$ are shown in Figures $7(\mathrm{a})$ and $(\mathrm{b})$.

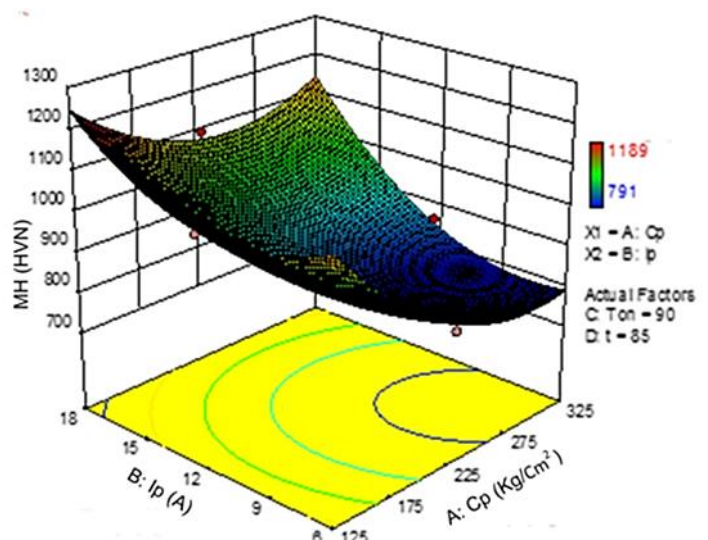

(a)

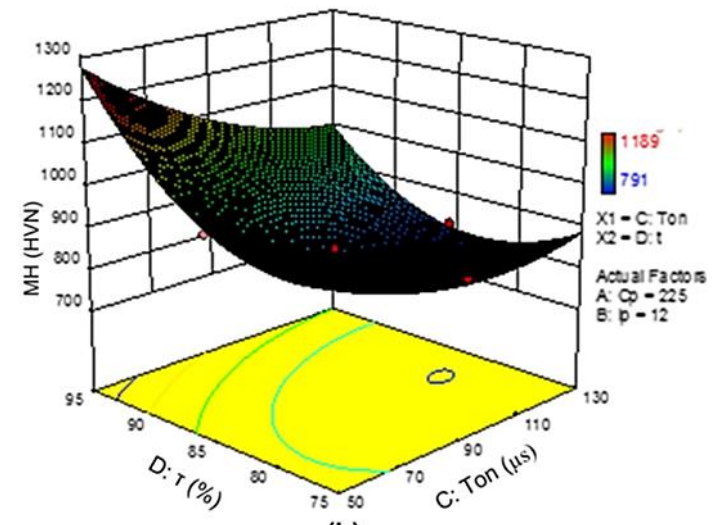

(b)

Figure 7. (a) Surface plot of MH vs. compaction pressure and peak current and (b) Surface plot of MH vs. pulse on time and duty cycle

Peak current and duty cycles are to be observed most significant parameters to contribute maximum microhardness. Effects on heating and cooling cycle were observed with high levels of peak current and duty cycle. Improvement in microhardness of thick modified recast layer were observed while varies peak current from 6 A to 18 A. Increase in microhardness is attributed to migration of hard constituents such as tungsten and silicon on substrate form P/M composite electrode [40].

\section{MULTI-RESPONSE OPTIMIZATION USING COMPOSITE DESIRABILITY}

In the present experimental work, two important responses such as SR and MH have been considered. However, objectives of both responses (minimum SR and maximum $\mathrm{MH}$ ) are conflict in nature and hence a single set of optimal solution for individual response will not fulfil the purpose. Therefore an appropriate multi-objective optimization technique called "composite desirability approach" has been selected to optimize responses.

Desirability function approach was described by Derringer and Suich in 1980. Recently, the problems associated with multi-response in manufacturing industries are solved using present method. The technique obtains a set of the best operating condition that gives the "most desirable" response value. The method makes use of an objective function $\mathrm{D}(\mathrm{X})$, known as the composite desirability function or utility transfer function. These methods transform each predicted response into a dimensionless (scale-free) value known as desirability for an individual response $\left(\mathrm{d}_{\mathrm{i}}\right)$ lies in a range of 0 to 1 . If the 
value of $\mathrm{d}_{\mathrm{i}}=1$, indicate idle case and $\mathrm{d}_{\mathrm{i}}=0$, indicate one or more responses are not within the acceptable boundaries. The geometric mean of individual response desirability with appropriate weight is known as composite desirability (D). The individual desirability $\left(\mathrm{d}_{\mathrm{i}}\right)$ for the response desirable to maximize is calculated as:

$$
\begin{array}{lc}
\mathrm{d}_{\mathrm{i}}=0 & \mathrm{X}_{\mathrm{i}}<\mathrm{L}_{\mathrm{i}} \\
\mathrm{d}_{\mathrm{i}}=\left\{\left(\mathrm{X}_{\mathrm{i}}-\mathrm{L}_{\mathrm{i}}\right) /\left(\mathrm{H}_{\mathrm{i}}-\mathrm{L}_{\mathrm{i}}\right)\right\}^{\mathrm{wi}} & \mathrm{L}_{\mathrm{i}} \leq \mathrm{X}_{\mathrm{i}} \leq \mathrm{T}_{\mathrm{i}} \\
\mathrm{d}_{\mathrm{i}}=1, & \mathrm{X}_{\mathrm{i}}>\mathrm{H}_{\mathrm{i}}
\end{array}
$$

If the response $X_{i}$ is to minimize, then the individual desirability $\left(\mathrm{d}_{\mathrm{i}}\right)$ is calculated as:

$$
\begin{array}{lrl}
\mathrm{d}_{\mathrm{i}} & =0, & \mathrm{X}_{\mathrm{i}}>\mathrm{H}_{\mathrm{i}} \\
\mathrm{d}_{\mathrm{i}}=\left\{\left(\mathrm{H}_{\mathrm{i}}-\mathrm{X}_{\mathrm{i}}\right) /\left(\mathrm{H}_{\mathrm{i}}-\mathrm{L}_{\mathrm{i}}\right)\right\}^{\mathrm{wi}} & \mathrm{L}_{\mathrm{i}} \leq \mathrm{X}_{\mathrm{i}} \leq \mathrm{H}_{\mathrm{i}} \\
\mathrm{d}_{\mathrm{i}}=1 & \mathrm{X}_{\mathrm{i}}<\mathrm{L}_{\mathrm{i}}
\end{array}
$$

Similarly the individual desirability $\left(\mathrm{d}_{\mathrm{i}}\right)$ for the response $\mathrm{X}_{\mathrm{i}}$ is at target $\left(\mathrm{T}_{\mathrm{i}}\right)$ can be calculated as:

$$
\begin{array}{lc}
\mathrm{d}_{\mathrm{i}}=0, & \mathrm{X}_{\mathrm{i}}<\mathrm{L}_{\mathrm{i}} \\
\mathrm{d}_{\mathrm{i}}=\left\{\left(\mathrm{X}_{\mathrm{i}}-\mathrm{L}_{\mathrm{i}}\right) /\left(\mathrm{T}_{\mathrm{i}}-\mathrm{L}_{\mathrm{i}}\right)\right\}^{\mathrm{wi}} & \mathrm{L}_{\mathrm{i}} \leq \mathrm{X}_{\mathrm{i}} \leq \mathrm{T}_{\mathrm{i}} \\
\mathrm{d}_{\mathrm{i}}=\left\{\left(\mathrm{H}_{\mathrm{i}}-\mathrm{X}_{\mathrm{i}}\right) /\left(\mathrm{H}_{\mathrm{i}}-\mathrm{T}_{\mathrm{i}}\right)\right\}^{\mathrm{wi}} & \mathrm{T}_{\mathrm{i}} \leq \mathrm{X}_{\mathrm{i}} \leq \mathrm{H}_{\mathrm{i}} \\
\mathrm{d}_{\mathrm{i}}=0, & \mathrm{X}_{\mathrm{i}}>\mathrm{H}_{\mathrm{i}}
\end{array}
$$

Where, $\mathrm{X}_{\mathrm{i}}=$ Predicted value of $\mathrm{i}^{\text {th }}$ response, $\mathrm{T}_{\mathrm{i}}=$ Target value for $\mathrm{i}^{\text {th }}$ response, $\mathrm{L}_{\mathrm{i}}=$ Lowest acceptable value for $\mathrm{i}^{\text {th }}$ response, $\mathrm{H}_{\mathrm{i}}=$ Highest acceptable value for $\mathrm{i}^{\text {th }}$ response, $\mathrm{d}_{\mathrm{i}}=$ Desirability for $\mathrm{i}^{\text {th }}$ response, $\mathrm{D}=$ Composite desirability, and $\mathrm{w}_{\mathrm{i}}=$ weight of desirability function of $\mathrm{i}^{\text {th }}$ response.

The next step is to obtain the composite desirability (D) by combining individual response desirability $\left(\mathrm{d}_{\mathrm{i}}\right)$. The composite desirability (D) is weighted geometric mean of the individual desirability for each response. The composite desirability is calculated as,

$$
\mathrm{D}=\left[\mathrm{d}_{1}{ }^{\mathrm{w} 1} \mathrm{x} \mathrm{d}_{2}{ }^{\mathrm{w} 2} \mathrm{x} \mathrm{d}_{3}{ }^{\mathrm{w} 3} \mathrm{x} \ldots \ldots \ldots \ldots \mathrm{d}_{\mathrm{n}}{ }^{\mathrm{wn}}\right]^{1 / \mathrm{n}}=\left[\Pi(\mathrm{di})^{\mathrm{wi}}\right]^{1 / \mathrm{w}}
$$

Where $\mathrm{n}=$ number of response and value of $\mathrm{w}_{\mathrm{i}}$ lying between 0 to 1 and $\mathrm{w}=\Sigma \mathrm{w}_{\mathrm{i}}$, the sum of $\mathrm{w} 1, \mathrm{w} 2, \mathrm{w} 3$, wn equals to one.

The set of input process parameters with maximum composite desirability is to be considered as optimal result. List of process parameters and responses with their goal, upper limit, lower limit, and levels of importance scale are given in Table 8. A set of first 10 optimal solutions were obtained with given constraints for SR and MH using Design Expert 10 software given in Table 9. The optimal set of process parameter which has highest composite desirability is given in Table 10.

Table 8. Criteria of input parameters and responses

\begin{tabular}{ccccc}
\hline Process parameter & Goal & $\begin{array}{c}\text { Lower } \\
\text { limit }\end{array}$ & $\begin{array}{c}\text { Upper } \\
\text { limit }\end{array}$ & Importance \\
\hline Compaction pressure $\left(\mathrm{C}_{\mathrm{p}}\right)$ & In range & 125 & 325 & 3 \\
Peak current $\left(\mathrm{I}_{\mathrm{p}}\right)$ & In range & 6 & 18 & 3 \\
Pulse on time $\left(\mathrm{T}_{\text {on }}\right)$ & In range & 50 & 130 & 3 \\
Duty cycle $(\tau)$ & In range & 75 & 95 & 3 \\
Surface roughness $(\mathrm{SR})$ & Minimize & 4.235 & 10.605 & 3 \\
Microhardness $(\mathrm{MH})$ & Maximize & 791 & 1189 & 3 \\
\hline
\end{tabular}


Table 9. Optimal sets of process parameters with their desirability

\begin{tabular}{ccccccccr}
\hline $\begin{array}{c}\text { Sr. } \\
\text { No }\end{array}$ & $\mathrm{C}_{\mathrm{p}}$ & $\mathrm{I}_{\mathrm{p}}$ & $\mathrm{T}_{\text {on }}$ & $\tau$ & $\mathrm{SR}$ & $\mathrm{MH}$ & Desirability & \\
\hline 1 & 150.252 & 6.000 & 50.190 & 87.649 & 4.501 & 1189.444 & 0.979 & selected \\
2 & 149.368 & 6.000 & 50.007 & 87.596 & 4.505 & 1192.001 & 0.979 & \\
3 & 151.333 & 6.001 & 50.000 & 90.029 & 4.506 & 1264.175 & 0.979 & \\
4 & 125.000 & 6.000 & 50.031 & 84.406 & 4.517 & 1202.418 & 0.978 & \\
5 & 148.808 & 6.000 & 50.000 & 88.044 & 4.517 & 1207.849 & 0.978 & \\
6 & 132.845 & 6.003 & 50.002 & 85.137 & 4.525 & 1189.000 & 0.977 & \\
7 & 145.861 & 6.000 & 50.000 & 87.288 & 4.525 & 1196.561 & 0.977 & \\
8 & 135.234 & 6.000 & 50.000 & 85.505 & 4.529 & 1189.002 & 0.977 & \\
9 & 140.616 & 6.000 & 50.000 & 86.307 & 4.531 & 1189.216 & 0.976 & \\
10 & 138.028 & 6.006 & 50.000 & 85.927 & 4.535 & 1189.008 & 0.976 & \\
\hline
\end{tabular}

Table 10. Optimal set of parameters for SR and MH

\begin{tabular}{ccc}
\hline Parameter & Goal & Optimum value \\
\hline Compaction pressure $\left(\mathrm{C}_{\mathrm{p}}\right)$ & In range & 150.3 \\
Peak current $\left(\mathrm{I}_{\mathrm{p}}\right)$ & In range & 6.00 \\
Pulse on time $\left(\mathrm{T}_{\text {on }}\right)$ & In range & 50.2 \\
Duty cycle $(\tau)$ & In range & 87.65 \\
\hline
\end{tabular}

\section{CONFIRMATION EXPERIMENT}

Once the set of optimal parameters based on composite desirability is obtained, the next step is to confirm predicted results. Experiments were performed on EDM setting optimal input parameters to validate the predicted value of responses obtained using Design Expert 10. The ramp function graph indicates the optimal value of individual parameters and responses with composite desirability shown in Figure 8.

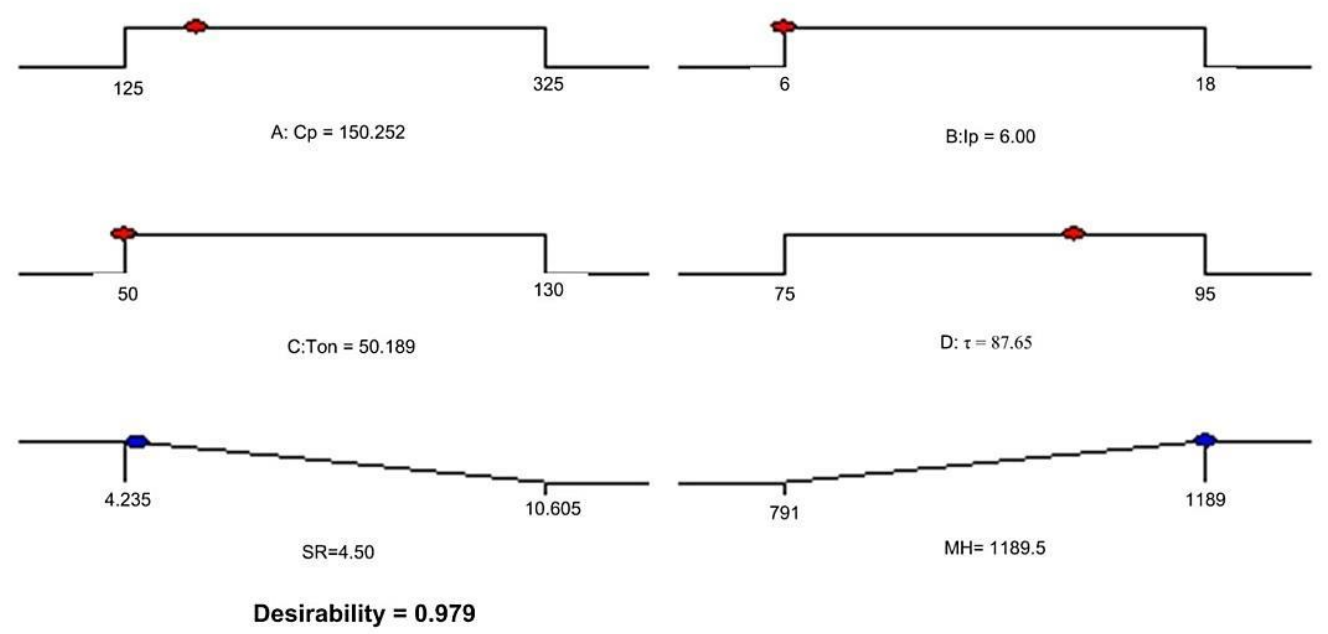

Figure 8. The ramp function for optimal composite desirability

The predicted result of responses and result obtained due to the performance of experiments on EDM are given in Table 11.The value of errors between predicted and experimental results of SR and MH lie within 5.26\% and $-3.64 \%$ respectively. A good agreement is observed between predicted response values and results obtained due to the performance of experiments on EDM. 
Table 11. Experimental validations of predicted responses

\begin{tabular}{ccccc}
\hline Responses & Predicted & Experimental & $\begin{array}{c}\text { Error } \\
(\%)\end{array}$ & $\begin{array}{c}\text { Composite } \\
\text { desirability }\end{array}$ \\
\hline Surface Roughness $(\mu \mathrm{m})$ & 4.5 & 4.75 & 5.26 & 0.979 \\
Microhardness $(\mathrm{VHN})$ & 1189.4 & 1146 & -3.64 & \\
\hline
\end{tabular}

\section{SURFACE CHARACTERIZATION}

In the present experimental work, two samples (Trial 8 and Trial 19) were selected for Scanning Electron Microscopy (SEM) and Energy Dispersive Spectroscopy (EDS) analysis [41]. SEM analyses of EDMed samples were carried out to confirm material migration from P/M electrode and formation of tungsten and silicon carbide. The Figure 9(a) shows the SEM image of AISI P20+Ni die steel EDMed with P/M electrode at compaction pressure $275 \mathrm{~kg} / \mathrm{cm} 2,15$-ampere peak current, $110 \mu$ s pulse on time and $80 \%$ duty cycle (Trial 8). Microcracks were formed due to uneven expansion and contraction of the thick recast layer. Compound formation and deposition were reported due to high heat energy at the high value of pulse on time. Deposition of debris on surface layer was responsible for rough surface. $\mathrm{Cu}-\mathrm{W}$ rich phase was clearly visible in microstructure with traces of copper at different locations which indicates migrations of P/M electrode elements on work material.
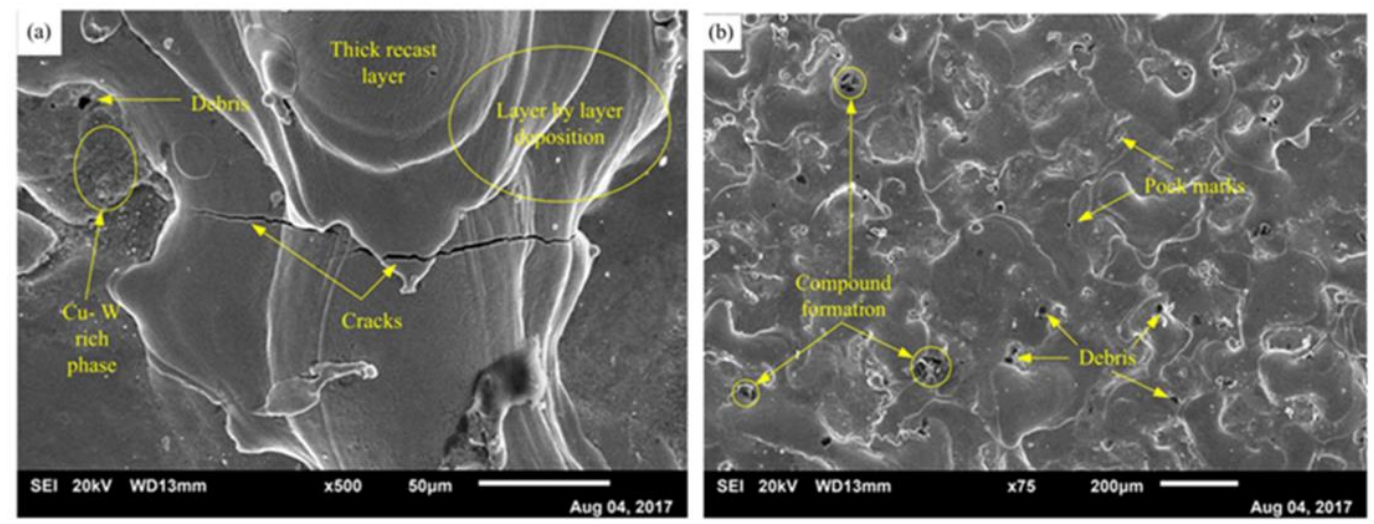

Figure 9. (a) SEM image for trial 8 and (b) SEM image for trial 19

The Figure 9(b) shows the SEM image of AISI P20+Ni die steel EDMed with P/M electrode at compaction pressure $225 \mathrm{~kg} / \mathrm{cm}^{2}$, peak current $6 \mathrm{~A} ; 90 \mu$ s pulse on time and $85 \%$ duty cycle (Trial 19) (Kumar et al., 2009). The SEM images show relatively very thin white layers due to a lower set of peak current. Further very few voids were observed because of lower heat energy. Copper enriched white boundaries were seen with a uniform distribution of small debris. Very small globules were formed at lower peak current.

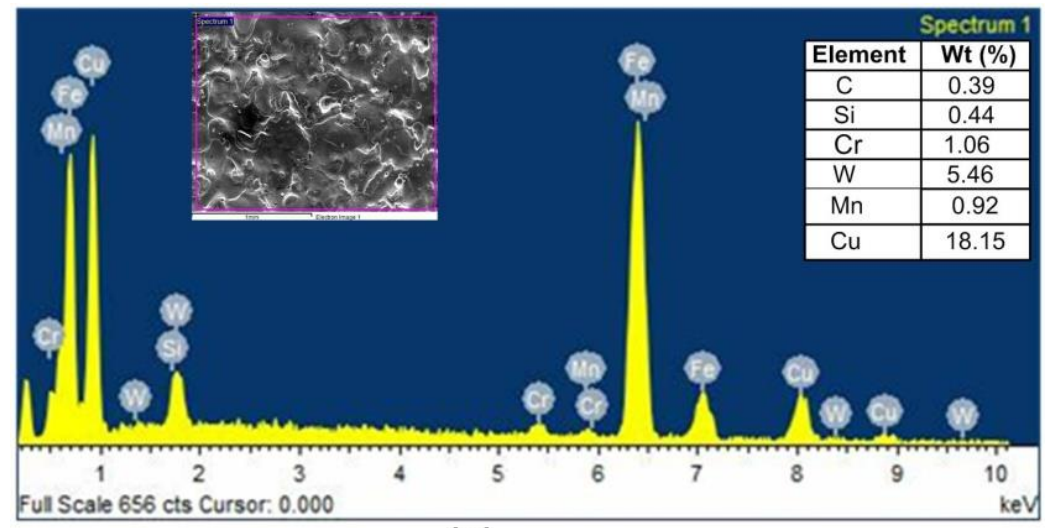

(a)

Figure 10. (a) EDS spectrum for trial 8

The results were obtained during EDS analysis indicates migration of significant amount of P/M electrode constituents such as copper, silicon, and tungsten migrated on the work surface. Improvement in carbon percentage was reported due to dissociation of hydrocarbon from dielectric fluid (EDM oil) [26]. The formation of carbide on work surface was 
observed due to the intermetallics bond between dissociated carbon elements from a dielectric with tungsten and silicon migrated from P/M electrode. Dispersion of hard particles and formation of carbides results in significant improvements in microhardness (Three times as compared to base material) of the EDMed work surface. The EDS spectrum of trial 8 and trial 19 with their compositions are shown in Figure 10(a) and (b) respectively [36].

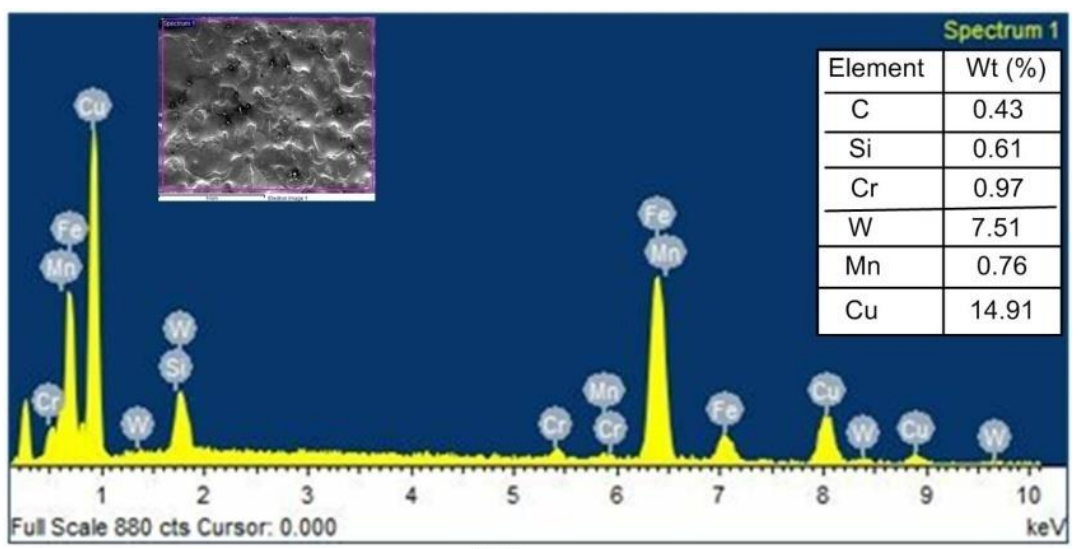

(b)

Figure 10. (b) EDS spectrum for trial 19

\section{CONCLUSIONS}

In this experimental work, the surface roughness and microhardness of AISI P20+Ni die steel samples machined on electrical discharge machine through powder metallurgy electrode were modelled and analysed using response surface methodology. Summarizing the main features of present experimental work, the following conclusions were drawn.

1. The good agreement was observed between predicted values and experimental values of responses such as SR with $\mathrm{R}^{2}$ of 0.9986 and $\mathrm{MH}$ with $\mathrm{R}^{2}$ of 0.9805 .

2. The P/M composite electrode offers three times improvement in the microhardness of work surface compared to the base material is attributed to the migration of hard constituents such as tungsten, silicon carbide, tungsten die carbide.

3. Using composite desirability approach, the optimal set of input parameters are compaction pressure 150.3 $\mathrm{kg} / \mathrm{cm}^{2}$, peak current 6.00 ampere, pulse on time $50.2 \mu \mathrm{s}$, and duty cycle $87.65 \%$ for achieving lower SR and higher MH.

4. The peak current was found to be the most significant parameter affecting on surface roughness and microhardness, followed by duty cycle and pulse on time.

5. The error between the predicted value and experimental value of responses at the optimal set of parameters for SR and MH maintain within $5.26 \%$ and $-3.64 \%$ respectively.

6. No major surface defects such as microcracks, voids, etc. are observed on the EDMed surface during SEM analysis. So, it can be concluded that the surface modification process performed on EDM using P/M electrode does not deteriorate the quality of the machined surface.

7. Presence of sufficient amount of copper with tungsten and silicon observed on the machined surface during the EDS analysis. Migration of P/M electrode constituents helps to improve the quality of the machined surface. No adverse effect of copper is observed on die steel surface.

8. The EDS analysis was favouring the migration of hardest constituents of P/M electrode on the work surface, which results improvement in microhardness of EDMed surface by more than three times as compared to base material.

\section{ACKNOWLEDGMENTS}

The authors would like to acknowledge Production Engineering Department, Government Engineering College, Bhavnagar, Gujarat, India for allowing to use EDM facility, Vicker microhardness tester and Surface roughness tester for experimentation. 


\section{REFERENCES}

[1] J. Simao, H. G. Lee, D. K. Aspinwall, R. C. Dewes, and E. M. Aspinwall, "Workpiece surface modification using electrical discharge machining," Int. J. Mach. Tools Manuf., vol. 43, no. 2, pp. 121-128, 2003, doi: 10.1016/S0890-6955(02)00187-6.

[2] Fuller John E, Electrical Discharge Machining, in ASM machining Handbook, vol. 16. 1996.

[3] K. A. Altan T, Lilly BW, Konig W, Tonshoff HK, Luttervelt CA, "Advanced techniques for die and mold manufacturing," Ann. CIRP, vol. 42(2), pp. 707-716, 1993.

[4] B. N. Lahiri, "Understanding EDM technology," Lect. notes Summer Program. Adv. Manuf. IIT Kharagpur, pp. 61-77, 2001.

[5] M. Y. Ali, A. Banu, M. Salehan, E. Y. T. Adesta, M. Hazza, and M. Shaffiq, "Dimensional accuracy in dry micro wire electrical discharge machining," J. Mech. Eng. Sci., vol. 12(1), pp. 3321 2018, doi: 10.15282/jmes.12.1.2018.4.0298.

[6] De Bruyn HE, "Slope control - a great improvement in spark erosion,” Ann. CIRP, vol. 16, pp. 183-186, 1968.

[7] H. S. S. P. C. Pandey, Modern Machining Processes. 1995.

[8] V. K. Jain, Advanced Machining Processes. Allied Publishers,New Delhi, India, 2004.

[9] M. A. R. Khan, M. M. Rahman, K. Kadirgama, M. A. Maleque, and M. Ishak, "Prediction of surface roughness of Ti-6Al-4V in electrical discharge machining: A regression model," J. Mech. Eng. Sci., vol. 1(9), pp. 16-24, 2011, doi: 10.15282/jmes.1.2011.2.0002.

[10] M. Y. Ali, M. A. Moudood, M. A. Maleque, M. Hazza, and E. Y. T. Adesta, "Electro-discharge machining of alumina: Investigation of material removal rate and surface roughness," J. Mech. Eng. Sci., vol. 10, pp. 16, 2017, doi: 10.15282/jmes.11.4.2017.5.0271.

[11] J. L. Ramdatti and A. V. Gohil, "Optimization of surface modification phenomenon for P20+Ni die steel sing EDM with P/M composite electrode,” pp. 689-697, 2020, doi: 10.1007/978-981-13-8196-6_60.

[12] H. K. Kansal, S. Singh, and P. Kumar, "Application of Taguchi method for optimisation of powder mixed electrical discharge machining,” Int. J. Manuf. Technol. Manag., vol. 7, pp. 329-341, 2005, doi: 10.1504/IJMTM.2005.006836.

[13] C. J. H. J. R. Crookall, "Electro-discharge machining - the state of the art," Ann. CIRP, vol. 20 (1), pp. 113-120, 1971.

[14] B. Mallick, B. R. Sarkar, B. Doloi, and B. Bhattacharyya, "Analysis on the effect of ECDM process parameters during micromachining of glass using genetic algorithm,” J. Mech. Eng. Sci., 2018, doi: 10.15282/jmes.12.3.2018.13.0344.

[15] J. M. Pujara, K. D. Kothari, and A. V. Gohil, "An investigation of material removal rate and kerf on WEDM through grey relational analysis," J. Mech. Eng. Sci., vol. 12(2), pp. 3633-3644, 2018, doi: 10.15282/jmes.12.2.2018.10.0322.

[16] G. B. F. X. Zeng, H Yu., "Failure Analysis of Die,” Beijing Mech. Ind. Press., 1987.

[17] B. M. Schumacher, "EDM technology for precision workpieces with excellent surface quality.," 1983.

[18] Z. Z.-Z. C. Peiyuan, "life and material of mold," Wuhan Wuhan Inst. Technol. Lect., 1994.

[19] Z. Luyang, "Die failure and protection," Beijing China Mach. Press, 1998.

[20] N. Mohri, N. Saito, M. Higashi, and N. Kinoshita, "A new process of finish machining on free surface by EDM methods," CIRP Ann. - Manuf. Technol., vol. 40(1), pp. 207-210,1991, doi: 10.1016/S0007-8506(07)61969-6.

[21] G. S. B. Singh, P. Singh, G. Tejpal, “An experimental study of surface roughness of H-11 in EDM process using copper tool electrode,” Int. J. Adv. Eng. Technol., vol. 3 (4), pp. 30-33, 2012.

[22] E. Unses and C. Cogun, "Improvement of electric discharge machining (EDM) performance of Ti-6Al-4V alloy with added graphite powder to dielectric," Stroj. Vestnik/Journal Mech. Eng., vol. 61, no. 6, 2015, doi: 10.5545/sv-jme.2015.2460.

[23] P. K. Patowari, P. Saha, and P. K. Mishra, "Taguchi analysis of surface modification technique using W-Cu powder metallurgy sintered tools in EDM and characterization of the deposited layer," Int. J. Adv. Manuf. Technol., 2011, doi: 10.1007/s00170010-2966-y.

[24] M. B. Ndaliman, A. A. Khan, and M. Y. Ali, "Formation of nitrides and carbides on titanium alloy surface through EDM," vol. 576, pp. 7-10, 2012, doi: 10.4028/www.scientific.net/AMR.576.7.

[25] A. Gangadhar, M. S. Shunmugam, and P. K. Philip, "Surface modification in electrodischarge processing with a powder compact tool electrode," Wear, 1991, doi: 10.1016/0043-1648(91)90084-8.

[26] N. Beri, S. Maheshwari, C. Sharma, and A. Kumar, "Performance evaluation of powder metallurgy electrode in electrical discharge machining of AISI D2 steel using Taguchi method," Int. J. Mech. Aerospace, Ind. Mechatron. Manuf. Eng., vol. 2, pp. 225-229, 2008

[27] A. Bhattacharya, A. Batish, and N. Kumar, "Surface characterization and material migration during surface modification of die steels with silicon, graphite and tungsten powder in EDM process," J. Mech. Sci. Technol., 2013, doi: 10.1007/s12206-0120883-8.

[28] A. S. Gill and S. Kumar, "Surface roughness and microhardness evaluation for EDM with Cu-Mn powder metallurgy tool," Mater. Manuf. Process., vol. 31, no. 4, pp. 514-521, 2016, doi: 10.1080/10426914.2015.1070412.

[29] S. Kumar, R. Singh, T. P. Singh, and B. L. Sethi, "Comparison of material transfer in electrical discharge machining of AISI H13 die steel," Proc. Inst. Mech. Eng. Part C J. Mech. Eng. Sci., 2009, doi: 10.1243/09544062JMES1227.

[30] T. A. El-Taweel, "Multi-response optimization of EDM with Al-Cu-Si-TiC P/M composite electrode," Int. J. Adv. Manuf. Technol., vol. 44, pp. 100-113, 2009.

[31] K. Furutania, A. Saneto, H. Takezawa, N. Mohri, and H. Miyake, "Accretion of titanium carbide by electrical discharge machining with powder suspended in working fluid," Precis. Eng., 2001, doi: 10.1016/S0141-6359(00)00068-4. 
[32] P. Peças and E. Henriques, "Influence of silicon powder-mixed dielectric on conventional electrical discharge machining," Int. J. Mach. Tools Manuf., 2003, doi: 10.1016/S0890-6955(03)00169-X.

[33] A. Das and J. P. Misra, "Experimental investigation on surface modification of aluminum by electric discharge coating process using TiC/Cu green compact tool-electrode,” Mach. Sci. Technol., 2012, doi: 10.1080/10910344.2012.731951.

[34] A. Batish, A. Bhattacharya, V. K. Singla, and G. Singh, "Study of material transfer mechanism in die steels using powder mixed electric discharge machining," 2012, doi: 10.1080/10426914.2011.585498.

[35] S. Kumar and U. Batra, "Surface modification of die steel materials by EDM method using tungsten powder-mixed dielectric," J. Manuf. Process., 2012, doi: 10.1016/j.jmapro.2011.09.002.

[36] P. Senthil, S. Vinodh, and A. K. Singh, "Parametric optimisation of EDM on Al-Cu/TiB2 in-situ metal matrix composites using TOPSIS method," Int. J. Mach. Mach. Mater., 2014, doi: 10.1504/IJMMM.2014.063922.

[37] G. Derringer and R. Suich, "Simultaneous Optimization of Several Response Variables," J. Qual. Technol., 1980, doi: 10.1080/00224065.1980.11980968.

[38] G. Talla, D. K. Sahoo, S. Gangopadhyay, and C. K. Biswas, "Modeling and multi-objective optimization of powder mixed electric discharge machining process of aluminum/alumina metal matrix composite," Eng. Sci. Technol. an Int. J., 2015, doi: 10.1016/j.jestch.2015.01.007.

[39] S. Tripathy and D. K. Tripathy, "Multi-attribute optimization of machining process parameters in powder mixed electrodischarge machining using TOPSIS and grey relational analysis," Eng. Sci. Technol. an Int. J., vol. 19(1), pp. 62-70, 2016, doi: 10.1016/j.jestch.2015.07.010.

[40] J. H. Jung and W. T. Kwon, "Optimization of EDM process for multiple performance characteristics using Taguchi method and Grey relational analysis," J. Mech. Sci. Technol., vol. 24(5), pp. 1083-1090, 2010, doi: 10.1007/s12206-010-0305-8.

[41] Y. Y. Tsai and C. T. Lu, "Influence of current impulse on machining characteristics in EDM," vol. 21(10), pp. 1617, 2007, doi: 10.1007/BF03177384. 